\title{
A tentative discussion on the monitoring of water resources in China
}

\author{
Yang Jianqing, Dai Ning, Wu Mengying, and Wang Guangsheng \\ Bureau of Hydrology of Ministry of Water Resources, Baiguang Road, Beijing, 100053, China \\ Correspondence to: Yang Jianqing (jianqing.yang@mwr.gov.cn) \\ Published: 17 October 2016
}

\begin{abstract}
With the rapid economy development and social civilization progress, the Chinese Government also is improving ecological environmental conditions. More efforts have been made to solve water problems through the implementation of stringent water resources management, as a key government policy on water. Thus, monitoring of water resources has been strengthened, being a main component of the hydrological work in recent years. Compared with routine hydrological monitoring, water resources monitoring pays more attention to the quantity and quality variations of regional waters, to reflect the status of water in river basins and administrative regions. In this paper, the overall layout of the hydrometric network in China is presented, monitoring efforts of the natural water cycle and water consumptions are analyzed, methodologies of water resources monitoring, which are commonly applied in the country, are summed up. Taking the hydrometric network planning on interprovincial boundary waterbodies as example, a summary of the planning at interprovincial boundary river sections is presented. The planning can meet the need of water resources management of administrative divisions. It can also improve the overall water resources monitoring for the country.
\end{abstract}

\section{Introduction}

Water is not only an irreplaceable natural resource, but also an important ecological and environmental element. According to the second National Water Resources Assessment in China, the total amount of water resources of the country was about 2841 billon $\mathrm{m}^{3}$ in early 21 st Century, which ranks the 6th place in the world. However, the amount of available waters in China per capita is about $2200 \mathrm{~m}^{3}$, only $28 \%$ of the world average, and the volume of water per unit land area is $83 \%$ of the world average. Moreover, China's water resources are spatially unevenly distributed. Where in southern region, land area accounts for $36 \%$ of the country, population accounts for $40 \%$, and the Gross Domestic Product (GDP) is about $56 \%$, with $81 \%$ of total water resources. While in northern region, the land area is about $64 \%$, population is about $46 \%$, and GDP accounts for $44 \%$, but the total water resources is only $19 \%$ of the country. The regional distribution of water resources in the country according to the China Water Resources Bulletin is shown in Fig. 1.

With the impact of climate change and human activities such as urbanization in the country, water scarcity due to changes of surface conditions in the north and water pollution in the south have not been effectively curbed. Contradiction between water supply and water demand is yet outstanding, and water utilization efficiency is still poor in comparison with those in developed countries.

In recent years, the Chinese Government devoted to promote the country's ecological and environmental condition by implementing stringent water management as a key policy on water. Three "red lines", i.e., (i) the control of total amount of water exploited, (ii) efficiency of water use, and (iii) water pollutions, have been set up in response to the increasing water problems across the country (Wang et al., 2015). To cope with the contradiction of temporally and spatially unevenly distributed available water and regional water consumptions, the Chinese Government also proposed the arduous task of inter-basin water transfer plans to realize regional water resources allocation. Above all, monitoring of water resources is the basis for the management of water. This paper introduces the overall hydrometric network in China, classifies the monitoring technology commonly applied in the country, and analyzes the comprehen- 

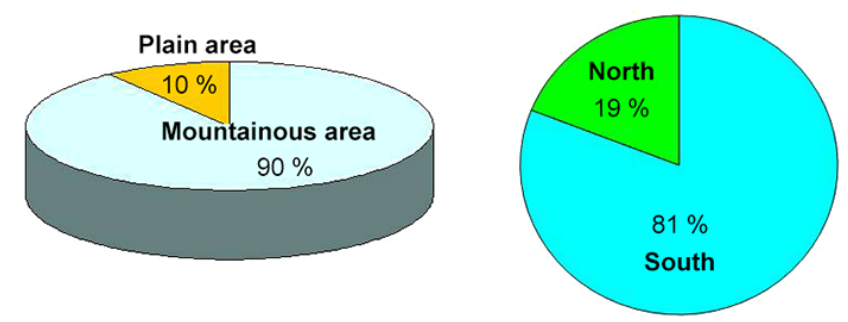

Figure 1. Distribution of water resources in China.

sive situation of water resources monitoring in China, taking the hydrometric network planning for interprovincial boundary rivers as an example. The distribution of monitoring stations at interprovincial boundary river sections is proposed to meet the needs of water resources management for provincial administrative divisions. The planning provides constructive guidance to the development of water resource monitoring of China.

\section{Hydrometric network development}

Water resource monitoring involves, for example, analyzing the water quantity, water quality, distribution of water status, and water exploitation, water utilization and conservation of water resources (Yao et al., 2013; Zhang et al., 2015). A hydrometric network is the basis for water resources monitoring, investigation, analysis and evaluation (Maidment, 1993; WMO Secretariat, 1988).

At present, water resources monitoring in China can be generally distinguished into two forms: dynamic monitoring for the natural water cycle and monitoring for water utilization. Where, dynamic monitoring for natural water cycle focuses on the monitoring of hydrological features of water bodies, including rivers, lakes, water channels, as well as regional groundwater. Monitoring for water utilization focuses on the monitoring of water supply, water use and water consumption processes through human activities, including water supply sources, water pipelines, sewage outlets and so on. For a long time, the dynamic monitoring of natural water cycle was given priority in the work of the hydrologic sector, while measurement of the water utilization status remains to be further improved. Following the implementation of stringent water management in recent years, monitoring for interadministrative boundary water sections become a new task to meet the needs of water resources management for administrative divisions. In addition, for those areas and water bodies without hydrological stations, water survey is usually carried out at a regular base, including both regional water quantity and water quality investigations.

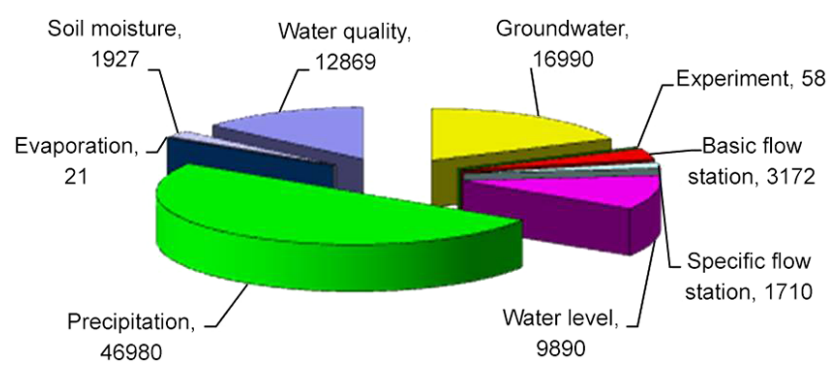

Figure 2. Structure of hydrological stations in China.

\subsection{Dynamic water resources monitoring}

After decades of development, China has established a comprehensive hydrological monitoring network all over the country, and accumulated a large amount of hydrological data, which provides a strong basis for the management of water resources. The hydrometric network has been long set up according to the needs of flood defence, drought relief and disaster reduction in river basins. Currently, there are in total 93617 different kinds of hydrological monitoring stations (Deng, 2015). The structure of the country's hydrological stations is shown in Fig. 2.

The dynamic monitoring of water resources based on existing hydrological stations is carried out, as follows.

i. Monitoring of surface water flow. Traditional hydrological monitoring stations are long deployed in line with the distribution of watersheds. The average density of national hydrological stations is $1966 \mathrm{~km}^{2} \mathrm{site}^{-1}$, where 3172 stations are the basic monitoring stations of main river control sections, 1710 hydrological stations are for intermediate and small rivers. Moreover, there are 46980 precipitation monitoring stations, 21 evaporation monitoring stations, and 1927 soil moisture monitoring stations. These provide a full coverage of major river basins all over the country. With the data collected, analysis of hydrological regime of rivers and calculation of runoff changes in basins can thus be made. Hydrological characteristics and water resources conditions of river basins can be evaluated to manage river flow and water storages, which provide a solid foundation for evaluation of regional water resources.

ii. Monitoring of groundwater level. There are 16990 groundwater monitoring stations in total, where 12898 stations are basic stations, which are monitored at a weekly base, and 4092 are supplemental stations, which are monitored seasonally. These stations form the basic groundwater monitoring network of China. Through monitoring, the dynamics of the regional groundwater level can be thus outlined, and groundwater storage changes can be estimated, which provide the basic needs of groundwater evaluation (Lin et al., 2005; Wang, 2014). However, most of the exist- 
Table 1. Summary of the planned monitoring stations distributed by main river basins.

\begin{tabular}{llllllll}
\hline & & & & \multicolumn{3}{c}{ Of which planned new stations } \\
\cline { 5 - 8 } Basin & $\begin{array}{l}\text { Basin area } \\
\left(10^{4} \mathrm{~km}^{2}\right)\end{array}$ & $\begin{array}{l}\text { Planning } \\
\text { stations }\end{array}$ & $\begin{array}{l}\text { Of which } \\
\text { existing } \\
\text { stations }\end{array}$ & Total & $\begin{array}{l}\text { Automatic } \\
\text { monitoring } \\
\text { sites }\end{array}$ & $\begin{array}{l}\text { Tour } \\
\text { gauging } \\
\text { sties }\end{array}$ & $\begin{array}{l}\text { Stationary } \\
\text { monitoring } \\
\text { sites }\end{array}$ \\
\hline Yangtze River & 180 & 248 & 87 & 161 & 4 & 133 & 24 \\
Yellow River & 368 & 85 & 60 & 25 & & 17 & 8 \\
Huaihe River & 33 & 89 & 34 & 55 & 2 & 40 & 13 \\
Haihe River & 32 & 199 & 103 & 96 & & 79 & 17 \\
Songliao River & 80 & 100 & 49 & 51 & & 43 & 8 \\
Pear River & 122 & 62 & 14 & 48 & & 36 & 12 \\
Taihu Lake & 27 & 58 & 12 & 46 & 33 & 9 & 4 \\
total & - & 841 & 359 & 482 & 39 & 357 & 86 \\
\hline
\end{tabular}

ing groundwater monitoring stations are distributed in northern China, and many are water extraction wells and irrigation wells, which are manually monitored. The present network density and regional layout cannot meet the increasing demand for information on water resources management. To strengthen and improve groundwater monitoring, the Ministry of Water Resources and the Ministry of Land Resources jointly proposed a project to measure the groundwater state through automatic monitoring systems (Qiao, 2009; Yang and Zhang, 2008). The project plans to construct a total number of 20401 automatic groundwater monitoring stations. Monitoring for groundwater overdraft areas and different groundwater sources are particularly strengthened. Effective monitoring will be achieved for most of the country's plains, which cover an area of 3.5 million $\mathrm{km}^{2}$.

iii. Monitoring of water quality elements. There are more than 12000 surface water quality monitoring sections, where, 596 sections focus on the monitoring of interprovincial boundary waters (buffer zones), 1507 sites are monitoring water supply sources, and 5064 sections are for the 4493 state-administrated water functional zones (areas defined according to the natural water conditions and regional development targets) across the country. In addition, water quality monitoring is carried out at both 4640 waste water outlets to rivers and 4115 representative groundwater monitoring wells.

To strengthen and promote the work of water quality monitoring, the Ministry of Water Resources completed the national water resources conservation monitoring planning in 2013. A total number of 16392 surface water quality monitoring sections are planned, providing a full coverage of the country's major water bodies. It can provide a strong support to the country's water conservation and protection goals by 2020 .

\subsection{Monitoring for administrative regions}

Following the step-wise implementation of a stringent water resources management, "three red lines" were formulated, i.e. a controlling index of the total amount of water exploited, efficiency of water use, and water pollutions for each administrative region. Among them, the controlling index of total exploited water for the country is 670 billion $\mathrm{m}^{3}$ by 2020 , and 700 billion $\mathrm{m}^{3}$ by 2030 . Thus, monitoring of water resources for trans-administrative boundary water bodies appeared to become essential for the implementation of stringent water resources management.

To examine and evaluate the government performance on rational water consumption and effective water conservation in the administrative regions, the Ministry of Water Resources has put forward the intensive monitoring for the trans-administrative boundary water bodies based on the monitoring network planning (Zhang et al., 2012). The planning focuses at the provincial administrative sections or at interprovincial boundary rivers. New hydrological stations were further deployed in comply with the existing hydrological monitoring network. Summaries of the planning are as follows, as an example.

i. Principle of the planning. Monitoring stations at provincial administrative sections of interprovincial boundary rivers are deployed to comply with following principles: (a) major river stems and their first-order tributaries, (b) rivers whose catchment area greater than $1000 \mathrm{~km}^{2}$, (c) key interprovincial water transfer project or interbasin water diversion project channels, (d) water vulnerable areas or seriously polluted areas of the interprovincial boundary water bodies.

ii. Outcome of the planning. Based on above principles, a total number of 841 monitoring stations are deployed at provincial administrative sections of interprovincial boundary rivers. Summary of monitoring stations distributed by main river basins are shown in Table 1. It is shown that, among the planned stations, 359 sites 
are existing monitoring stations, accounting for $43 \%$ of the total number, while 482 sites are new stations, accounted for $57 \%$ of the planning. To promote the automatic monitoring capacity, $82 \%$ of the new sites are either tour gauging or automatic monitoring stations. To meet the requirement of monitoring regulations of water resources, monitoring of water quality will be synchronized with monitoring of water flow for all the 841 sites. Sketch map of the planned hydrological monitoring stations for interprovincial boundary rivers is shown in Fig. 3.

In the planning, there are 367 interprovincial boundary rivers, whose drainage areas are above $1000 \mathrm{~km}^{2}$. Monitoring stations for 333 interprovincial boundary rivers at their provincial administrative sections are implemented, which account for $91 \%$ of the total number of 367 rivers. Among which, 213 rivers are deployed with existing monitoring stations, accounting for $58 \%$ of the total number of interprovincial boundary rivers. Analysis is further made by the method of area-runoff depth correlation algorithm. It shows that, with the planned monitoring capacity, an average $86 \%$ of total inflow and $88 \%$ of total outflow for provincial administrative regions can be effectively examined. Remaining rivers without planned stations are mostly located in mountainous areas, which are deserted areas with little water management demands. Taking into account the work done for ungauged areas, the planning can meet the increasing needs of regional water management for provincial administrative divisions.

\subsection{Monitoring for water use}

Monitoring for water use is usually carried out in real-time through monitoring stations. However, for those areas without monitoring stations, it can also be made through water investigation.

i. Monitoring for water consumptions. In comparison with the dynamic monitoring of the natural water cycle, monitoring for water consumptions is relatively weak in China. The monitoring ability is poor when compared with those developed countries (Martin, 2008; Office of the Auditor General of Canada, 2010; Wang et al., 2014). At present, a statistic method, such as water consumption quotas, is widely used for the measurement of water consumption in China. Nearly $30 \%$ of industrial and $70 \%$ of agricultural water use have not yet been directly metered. Based on the current monitoring situation, following principles are set up to strengthen the real-time monitoring of water consumptions by focusing on those important users: (a) centralized public and industrial users with annual surface water consumptions above 300 million $\mathrm{m}^{3}$, (b) licensed public and industrial users with annual groundwater consumptions above 50 million $\mathrm{m}^{3}$, and (c) users taken water from vulnerable and sensitive water-bodies for specific pur- pose. Based on the principle above, a pilot project on comprehensive water resources monitoring and management for 38 cities in 22 provinces has been established by the Ministry of Water Resources. The project provides online monitoring for 2891 drinking water sources, large water users, groundwater overdraft areas and water functional zones since 2006. Starting from 2012 , a state project on water resources monitoring capacity building has been put forward. Online monitoring of 8558 key water users at national level, including 5576 surface water users, 2886 groundwater water users, and 96 locations with conjunctive use of surface and groundwater have been further put into practice. In combination with the monitoring carried by local counties, around $80 \%$ of the total licensed water thus can be effectively monitored.

ii. Water investigation. Water investigation is carried out at regular basis for those areas without monitoring stations. Investigation for water flow is conducted once a year in general, and investigation for waste water into rivers and lakes is generally conducted every 1 to 3 years. These investigations are carried out in accordance with the Technical Guideline for Water Resources Monitoring. The main technical work is as follows: (a) investigation of natural water quantity, including river channel flow, inflow and outflow of interprovincial boundary rivers, water storage and groundwater, (b) investigation of water exploitation and utilization, including surface water consumptions, groundwater exploitation, groundwater recharge, mining drainage survey, and (c) specific investigations, including industrial and domestic wastewater into rivers and lakes, irrigation return flow.

Analysis shows that, a comprehensive hydrometric network has been developed in China. The spatial distribution of hydrological stations is by far rational and practical. The network distribution and monitoring elements are basically consistent with regional economic and social development patterns. However, due to the spatially and temporally unbalanced economic development of the country, the hydrological monitoring network has also been unevenly distributed. It is clear that, the monitoring network for water utilization is still insufficient. Particularly, those monitoring stations for inter-administrative boundary rivers are inadequate and monitoring for water exploitation and consumption are poor. Demands for timely and fully understanding of the regional water situation cannot be satisfied. There is an urgent need to accelerate the implementation of the designed monitoring network.

\section{Application of monitoring technology}

Traditional hydrological monitoring technology and methodology are fully applied in the monitoring of water resources. 


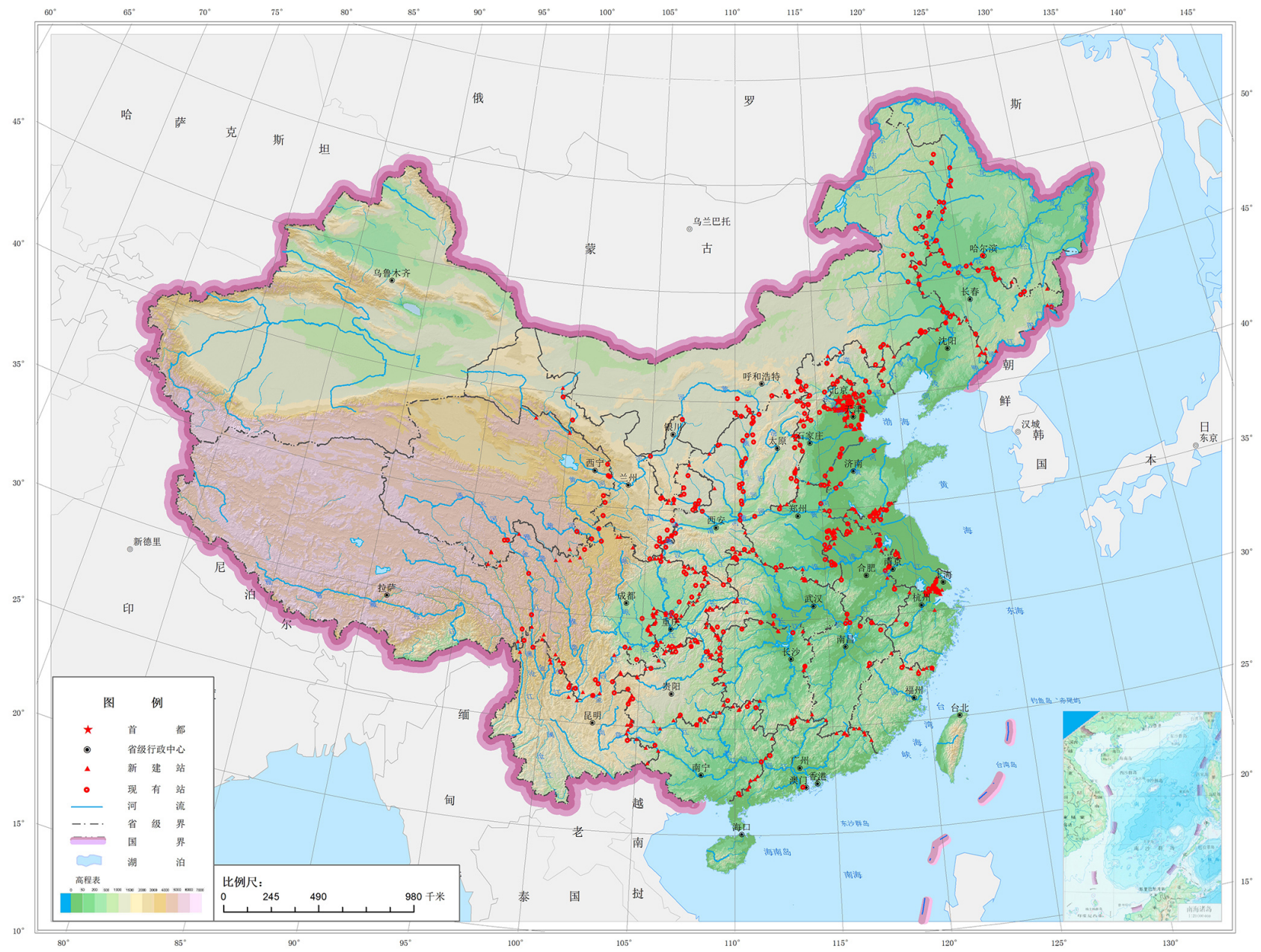

Figure 3. Sketch map of the planned hydrological monitoring stations for interprovincial boundary rivers.

With the rapid development of modern science and technology, automatic monitoring technology has also been widely introduced in water resource monitoring (Yao et al., 2013; Zhang et al., 2003). Some examples of technology of main hydrologic elements monitored are as follows:

i. Monitoring of water levels. Currently, automatic monitoring of water levels is extensively applied in the country. According to statistics, more than $90 \%$ of the surface water levels in the country are automatically monitored. However, about $90 \%$ of groundwater monitoring is still manually done. The capacity of automatic monitoring of groundwater will be significantly improved after the implementation of the state automatic groundwater monitoring system. For automatic water level monitoring, the float type, pressure type and bubble type water level meters are the main instruments applied for both surface water and groundwater. According to the technical regulations on water level monitoring, some manual checks of the water level is still necessary for the automatic monitoring sites. It is mainly used to cross check the automatic measurement instruments by manual readings.

ii. Monitoring of open channel flow. Open channel flow monitoring methods in China is done through the velocity-area method, hydraulics methods, tracer methods and volumetric methods (Yang et al., 1993). Velocity-area method is the most commonly used monitoring technology. Where, the point velocity-area method is the most widely applied one. Nearly $80 \%$ of the current national basic hydrological stations utilize the point velocity-area method, whose most popular measurement instrument is the rotor type flow meters. Application of the Acoustic Doppler Current Profilers (ADCP) in China has constantly been increasing over the last decade (Liu et al., 2006). Up to $50 \%$ of the hydrological stations in the recent monitoring planning for small and medium-size rivers uses the velocity-area method of current profiler type. In addition, when steady hydrological condition of the monitoring cross sections can be achieved, and reliable and stable water level-flow 
correlation can be established, then people are encouraged to make use of the rating-curve instead of the direct flow measurement.

iii. Monitoring of pipe flow. Monitoring for pipe flow can also be distinguished as velocity-area method and volumetric method in principle. For the monitoring of industrial and domestic pipe flow, both methods are extensively used. Types of popular instruments include the electromagnetic flow meter, acoustic flow meter, water meter and others. For the monitoring of irrigation water, above monitoring technology can generally be applied. While for the measurement of groundwater exploitations, indirect measurement such as electricity use, irrigation water meter and water consumption quotas are the typical methods utilized.

iv. Monitoring of water quality. Water quality monitoring can generally be divided into two kinds, one is the manual monitoring, and the other is automatic measurement (Chen et al., 2014). At present, no matter if it is surface water, groundwater, a natural water body or an artificial pipeline, manual sampling in combination with laboratory analysis is still the main method for water quality monitoring. Limited parameters are monitored through automatic measurement of the electrode method and online analysis technology.

v. Monitoring of precipitation, evaporation and water storage. For the monitoring of water storage, water levels are automatically monitored, and the storage capacity of reservoirs and other water bodies are usually obtained through the water level-volumetric correlations. For the monitoring of precipitation, automatic monitoring has been realized for all stations; while pan evaporation will remain to be manually monitored in general.

\section{Discussions and suggestions}

Water resource monitoring is important for better understanding of regional water conditions and for evaluation of water resources. In this paper, the overall hydrometric network in China is introduced, and the classification of the monitoring network and monitoring technology commonly applied in the country are presented. As an example, the monitoring network planning for interprovincial boundary rivers is demonstrated to meet the increasing demand of water management. It can be seen that in recent years, much attention has been paid to the monitoring of water resources in China. The water resources monitoring provides a reliable scientific basis for water exploitation, utilization, configuration, protection and conservation. Strengthening the monitoring of water resources is not only the requirement of implementing stringent water resources management, but it also is an important part of the development of hydrological work.
In recent years, China has been facing serious water problems, including water shortage, water pollution, and inefficient water use, while water resource monitoring still was fundamentally weak. Current monitoring cannot meet the actual needs of water management yet. In view of the outstanding problems in current water resources monitoring, the following suggestions are made on the establishment of a systematic monitoring network:

i. Traditional hydrological monitoring mainly focused on the monitoring of hydrological elements of the natural water cycle, including its spatial and temporal distributions, to better understand regional water quantity and quality conditions. Future monitoring of water resources should be put forward to comply better with the regional water status. Synchronized water quantity and water quality monitoring, regional water balance assessment in combination with measurements and investigations, should be implemented in water resource monitoring.

ii. Considering the relatively weak water resources monitoring, especially the monitoring of water exploitation and consumption in the country, there is an urgent need to accelerate the implementation of monitoring planning of the interprovincial boundary river sections, as well as the planning of the water resources monitoring capacity-building and automatic groundwater monitoring. Thus, the monitoring network can be optimized, network density can be improved, and water resources monitoring can be strengthened.

iii. Taking into account the cost of human resources for stationary monitoring stations, it is required to actively promote automatic monitoring to increase the water resources monitoring. Monitoring frequency and accuracy could also been improved, to satisfy the growing demand for water resources management.

\section{Data availability}

The "Directory of rivers to be carried out for water allocation (monitoring and assessment) during the period of 20132015", which is the basic data for the work of hydrometric monitoring planning on inter-provincial boundary river sections is avaible in the Supplement. Access to the hydrometric network data in part1 of the manuscript is available on the government web (http://www.mwr.gov.cn/zwzc/hygb/ swqknb/, Bureau of Hydrology of Ministry of Water Resources, 2015).

\section{The Supplement related to this article is available online at doi:10.5194/piahs-93-85-2016-supplement.}


Acknowledgements. The work is supported by Zhang ShuAn from the Bureau of Hydrology of the Ministry of Water Resources. Special thanks to Henny A. J. van Lanen from the Wageningen University for his comments and revision to improve the paper.

\section{References}

Bureau of Hydrology of Ministry of Water Resources: 2014 Annual Report of National Hydrological Statistics, Shangdong Hydrological Press, Shangdong, China, http://www.mwr.gov.cn/zwzc/ hygb/swqknb/, 2015.

Chen, Z. Z, Yin, J., and Liang, S. S: Outlook for automatic water quality monitoring applied in Yangtze Estuary, Water Purification Technology, 33, 81-83, 95, 2014.

Deng, J.: 2014 Annual Report of Hydrological Development, Shandong Hydrological Publishing House, Shangdong, China, 37-40, 2015.

Lin, Z. D., Liu, H. S., Jiang, Y. X., Cheng, Y. L., and Zhang, H.: Technical standard for groundwater monitoring, Chin Waterpower Press, Beijing, China, 2005.

Liu, D. S., Jin, X. P., Zhu, X. Y., Zhou, F. Z., and Wei, J. C.: Code for discharge measurement of acoustic Doppler current, China Waterpower Press, Beijing, China, 2006.

Maidment, D. R.: Handbook of Hydrology, McGraw-Hill, 1993.

Martin, G. (Ed.): Water Framework Directive, translated by: International Economic and Technical Cooperation Center of the Ministry of Water Resources, China Waterpower Press, Beijing, China, 2008.

Office of the Auditor General of Canada: Network design for water quality monitoring of surface freshwaters: a review, 2010 Fall Report of the Commissioner of the Environment and Sustainable Development, 1-17, 2010.

Qiao, G. J.: Study on the functional area of groundwater in China, China Hydrology, 29, 90-93, 2009.
Wang, R.: Real time monitoring and analysis of shallow freshwater resources, Resources and Environment, 18, 115-116, 2014.

Wang, X. K., Qu, Y., Zhi, Y., and Ren, Y. F.: The monitoring system for long-term urban ecosystem study in USA and China, Advances in Earth Science, 29, 617-623, 2014.

Wang, X. J., Zhang, J. Y., Shamsuddin, S., He, R. M., Xia, X. H., and Mou, X. L.: Potential impact of climate change on future water demand in Yulin city northwest China, Mitigation and Adaptation Strategies for Global Change, 20, 1-19, 2015.

WMO Secretariat: Water resources assessment activities: handbook for national evaluation, UNESCO Paris, World Meteorological Organization, Geneva, 1988.

Yang, Y. C., Chen, H. F., Wang, B. C., Zhu, X. Y., and Wang, Y. C.: Code for liquid flow measurement in open channels. China Waterpower Press, Beijing, China, 1993.

Yang, J. Q. and Zhang, S. A.: General discussion on groundwater monitoring and prediction studies in China, in: Proceedings of the Symposium on Water Ecological Monitoring and Analysis, Shandong Atlas Publishing House, Shandong, China, 207-211, 2008.

Yao, Y. X., Zhang, S. A., Yang, J. Q., Fang, R., and Yang, G. L. (Eds.): Water resource information monitoring and transmission technology, Hohai University Press, Nanjing, China, 2013.

Zhang, J. Y., Zhu, C. N., Cui, J. J., Tang, Z. S., and Xu, Z. C.: Technical specification for hydrologic data acquisition system, China Waterpower Press, Beijing, China, 2003.

Zhang, S. A., Yang, J. Q., Lin, Z. D., Fang, R., Yang, G. L., Wei, Y. H., and Li, S. B.: Discussion on the outline of water resources monitoring network planning in China, in: Proceedings of the Conference on Academic Hydrology 2012, Hohai University Press, Nanjing, China, 337-343, 2012.

Zhang, S. A., Zhang, L. Z., Fang, R., Ding, F., Jing, Y., Yuan, Y. P., and Dai, N.: Technical guideline for the monitoring of water resources quantity, China Waterpower Press, Beijing, China, 2015. 